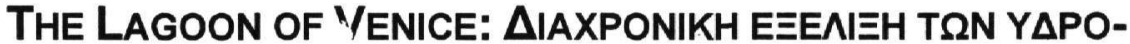

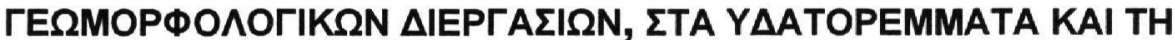

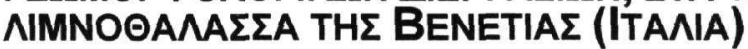

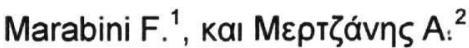 \\ ${ }^{1}$ Consiglio Nazionale delle Ricerche, Istituto di Geologia Marina, Via P. Gobetti 101, 40129 \\ Bologna, Italy, franco.marabini@bo.ismar.cnr.it
}

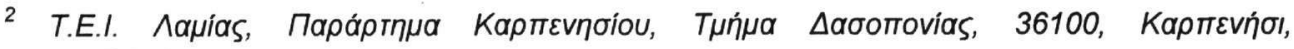
amertz@hol.gr

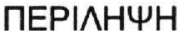

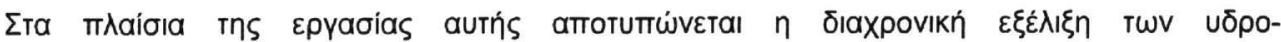

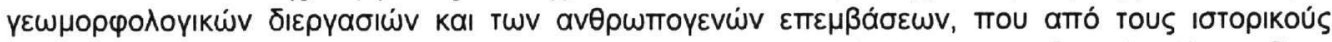

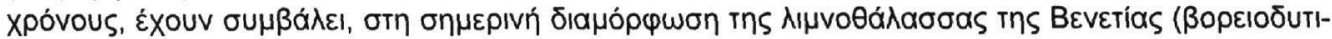

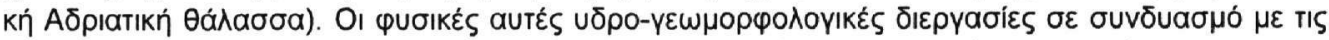

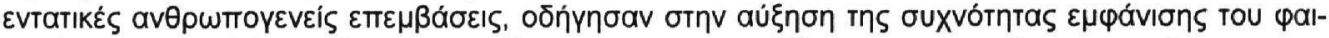

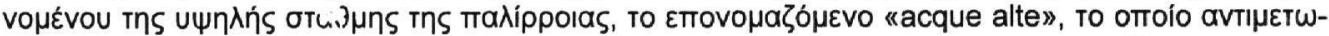

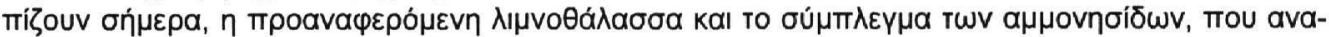

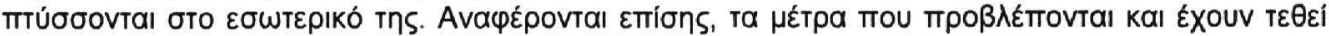

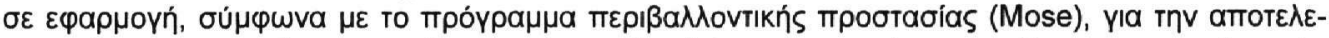

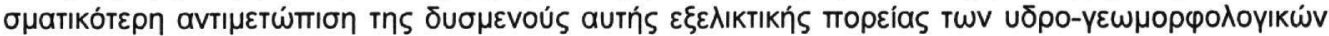

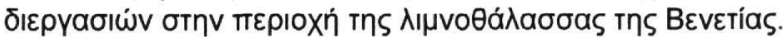

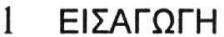

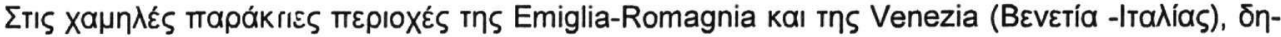

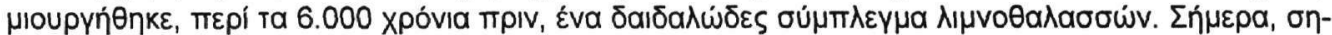

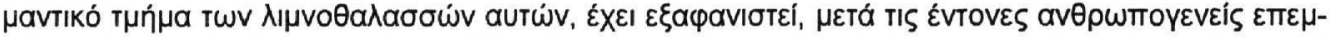

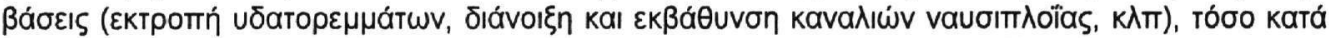

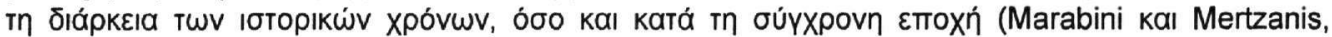

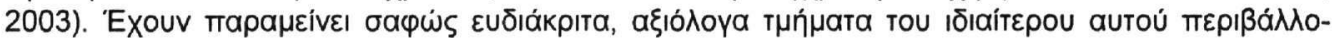

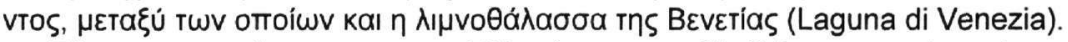

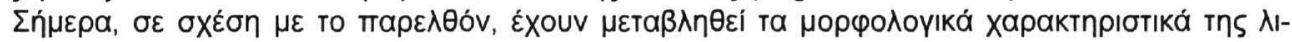

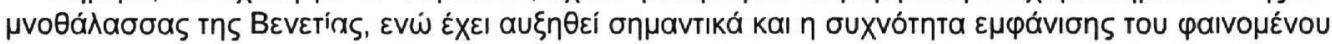

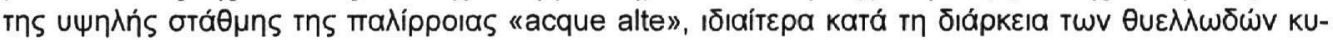

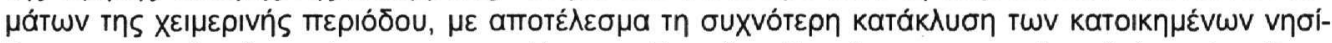

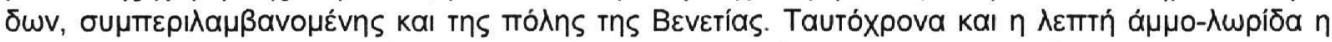

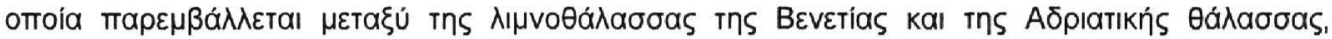

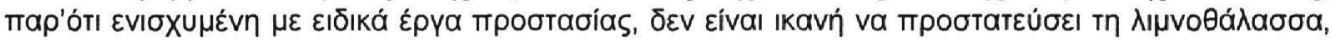

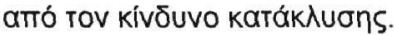

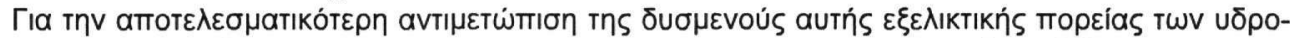

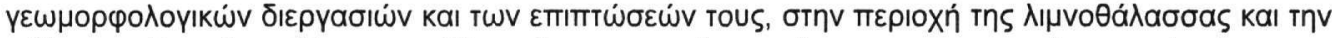

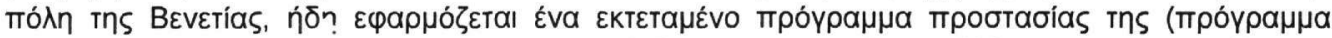

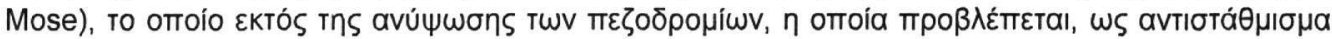

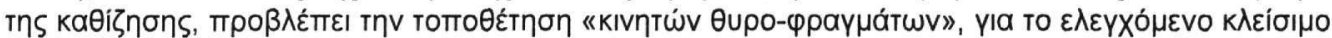

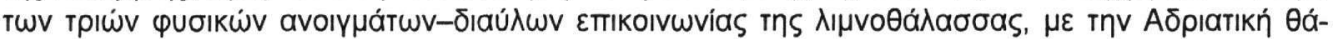

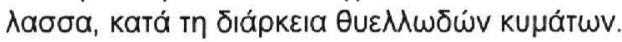




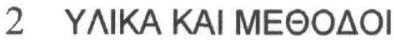

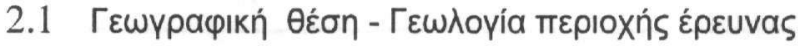

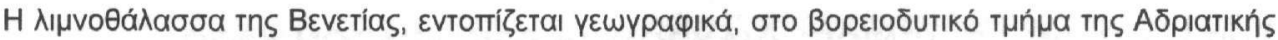

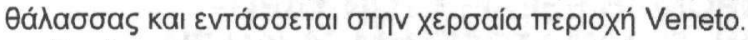

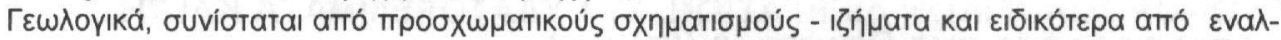

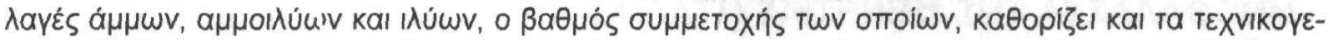

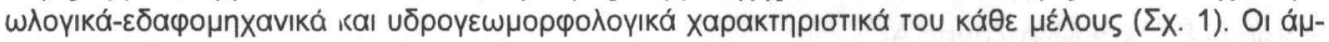

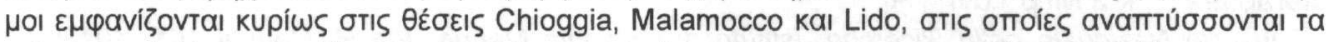

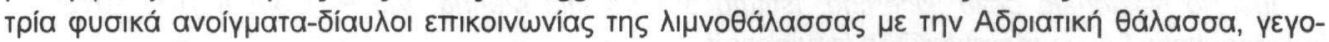

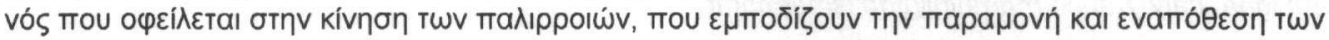

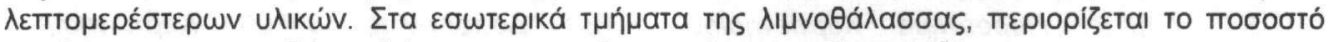

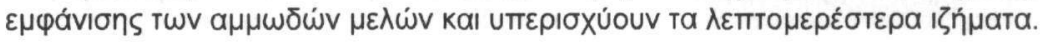

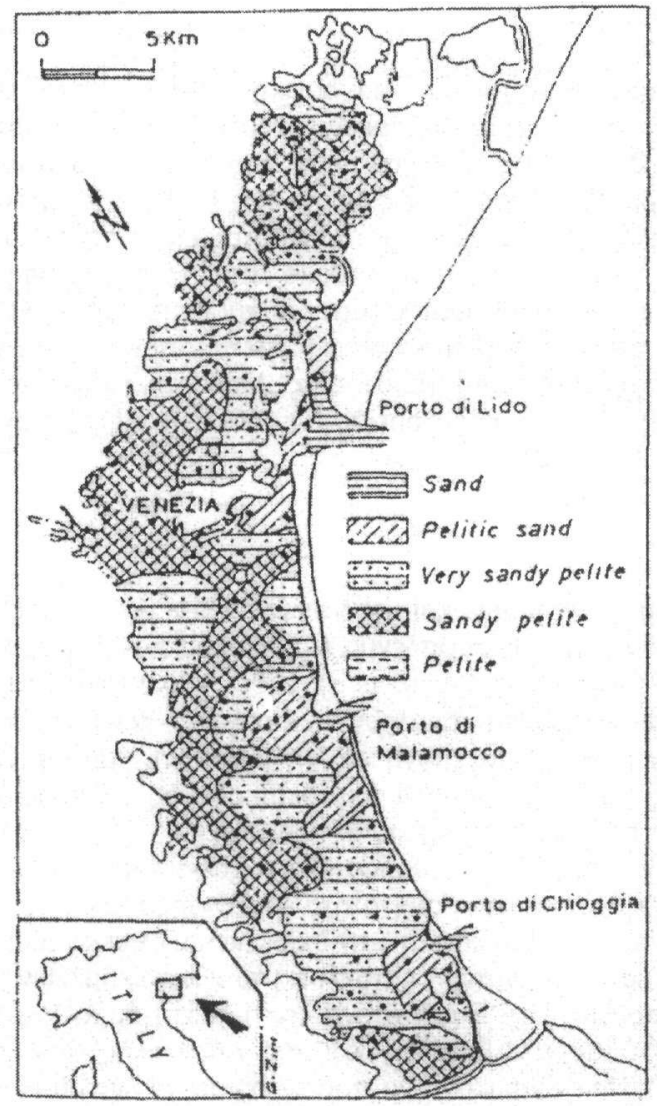

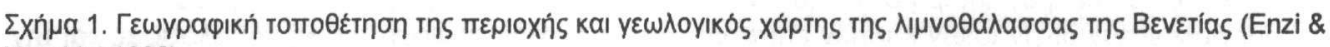
Marabini 1992).

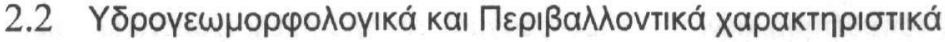

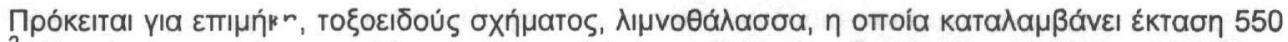

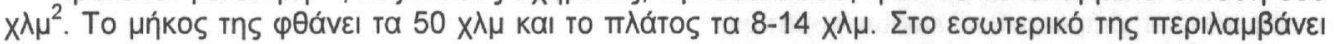

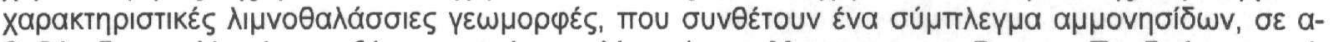

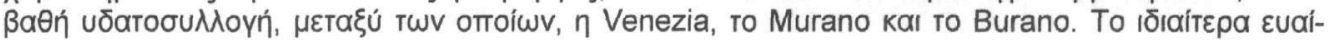




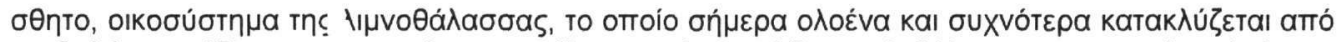

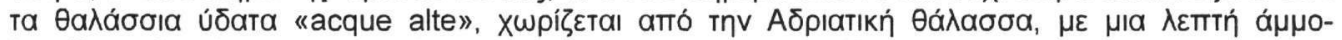

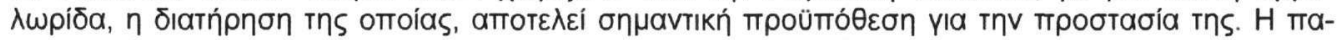

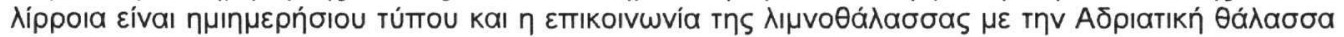

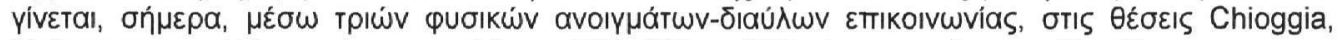

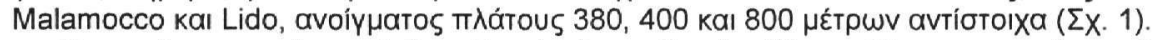

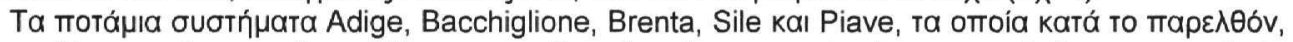

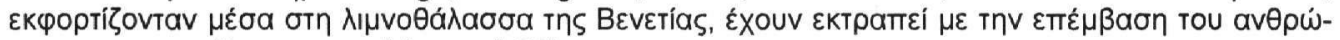

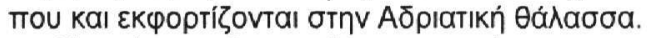

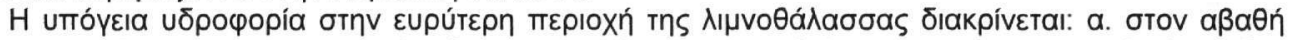

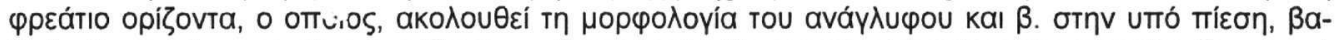

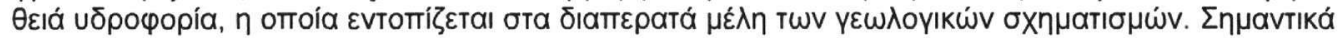

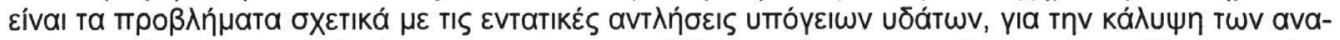

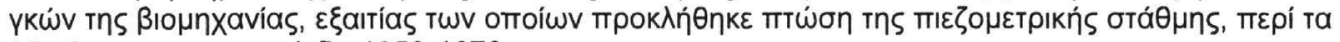

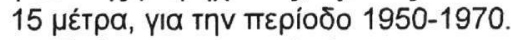

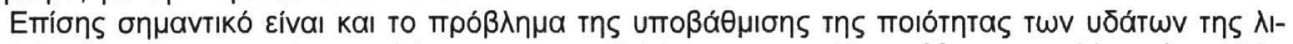

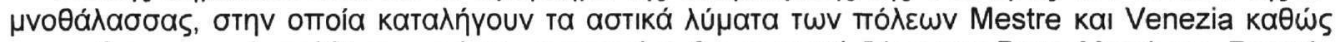

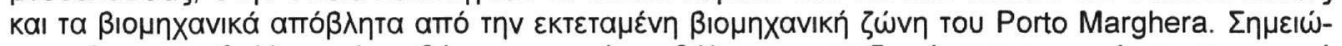

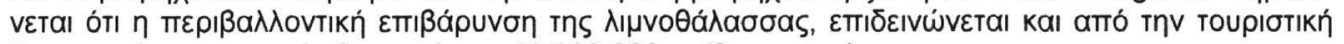

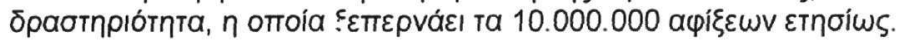

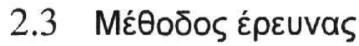

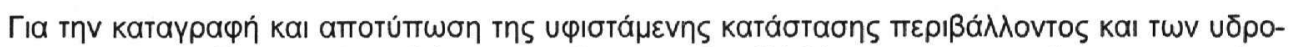

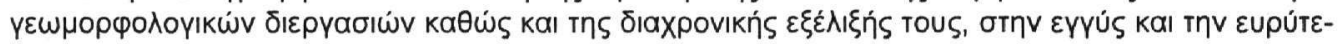

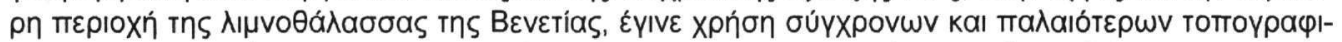

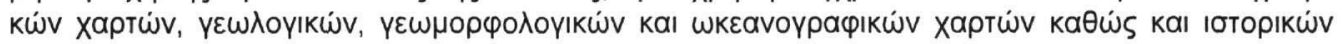

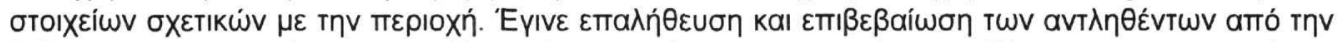

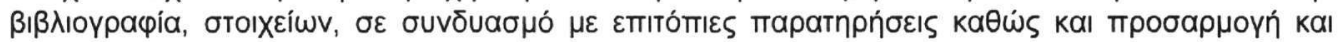

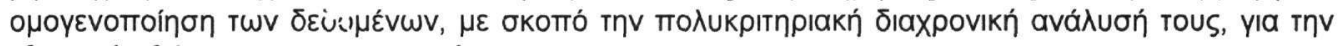

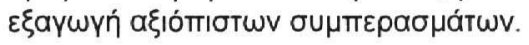

\section{3 АПОTЕАЕ}

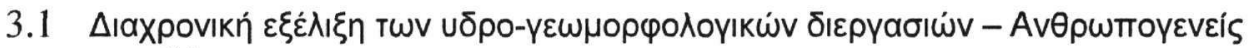 $\varepsilon \pi \varepsilon \mu \beta a ́ \sigma \varepsilon \mid \zeta$}

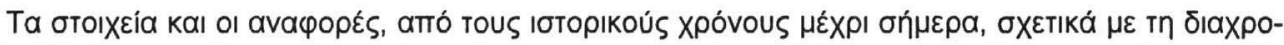

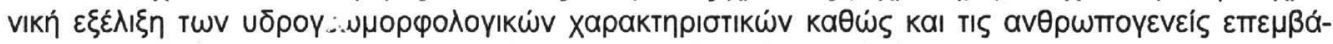

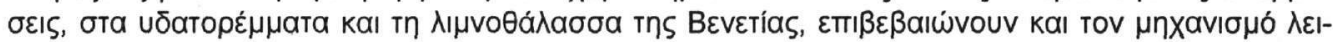

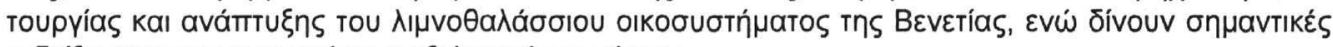

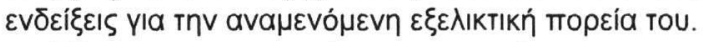

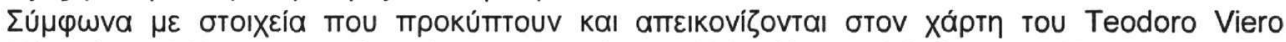

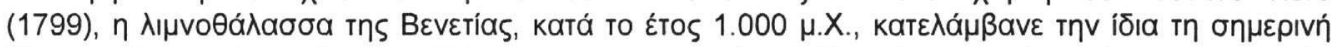

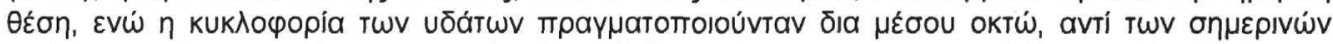

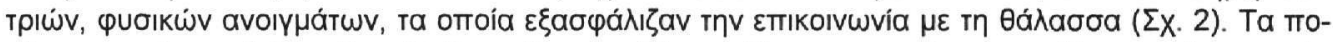

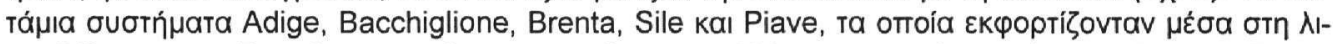

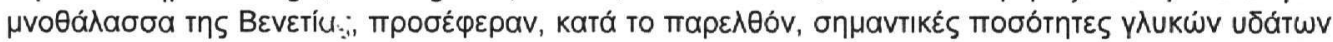

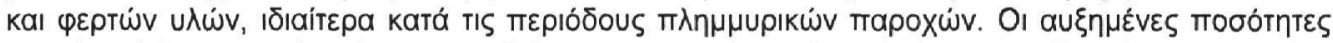

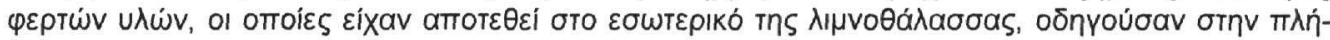

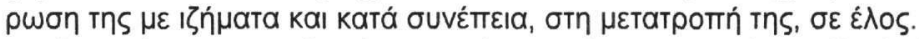

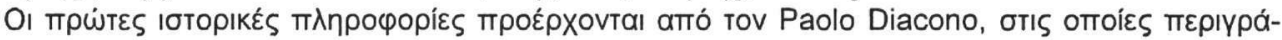

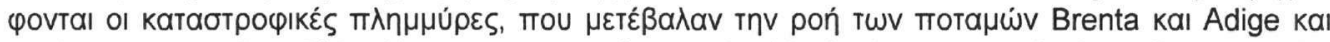

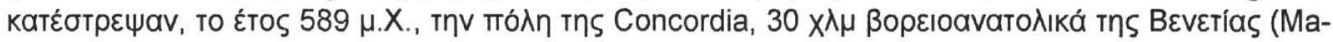

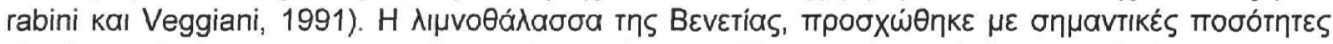

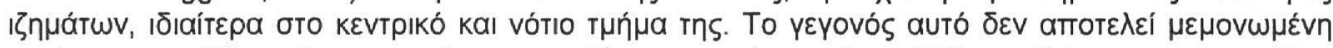

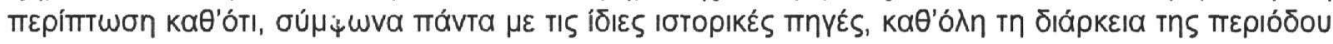




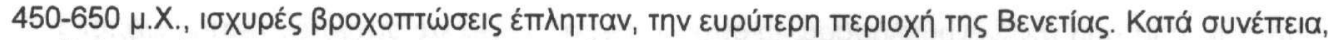

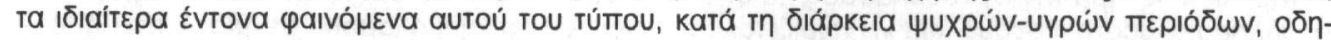

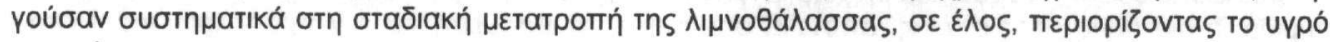
бтоххі́о.

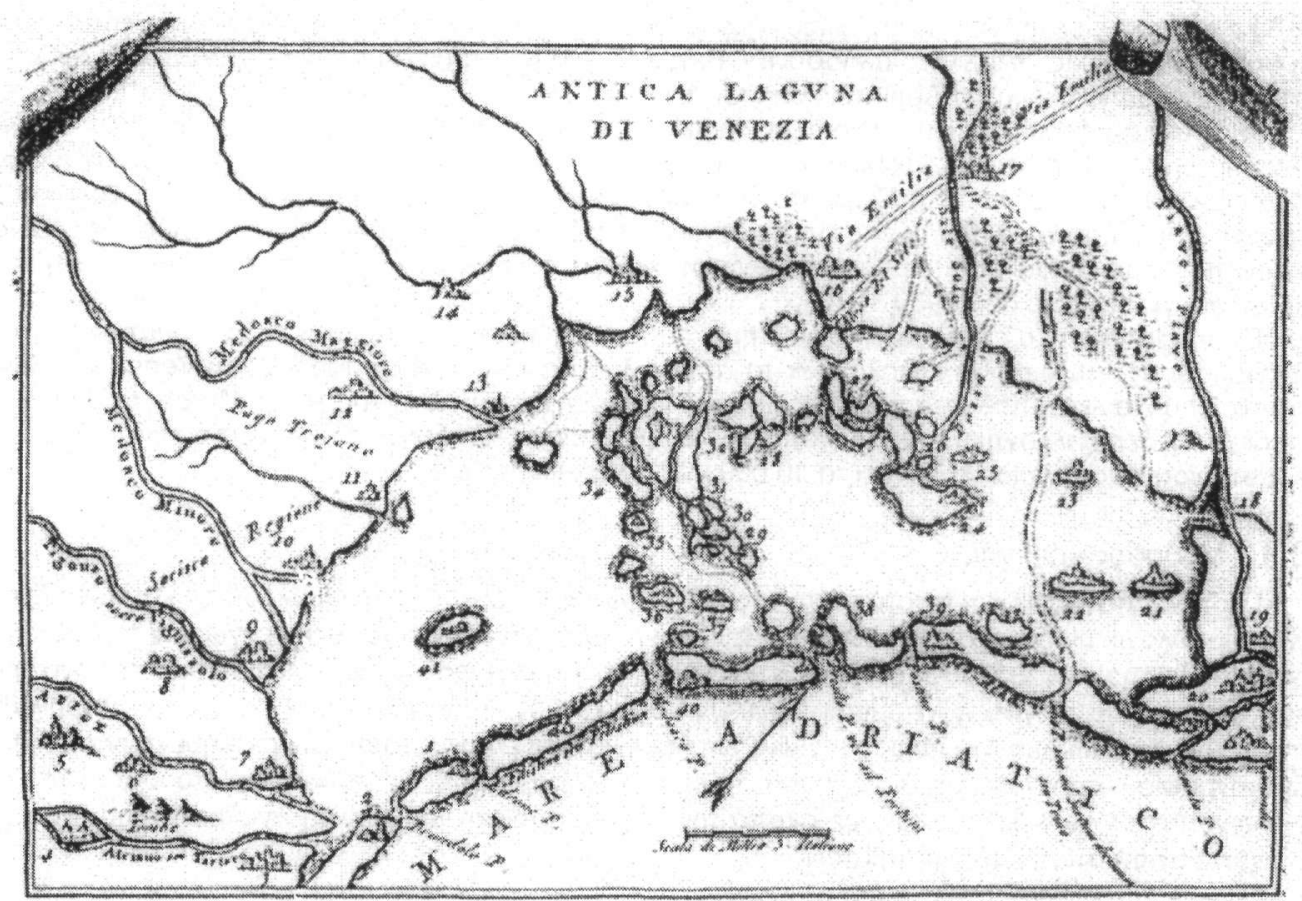

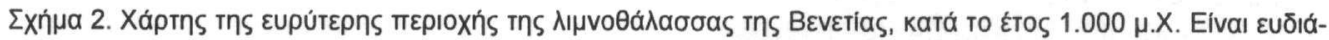

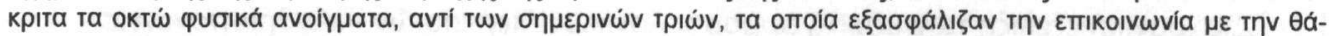

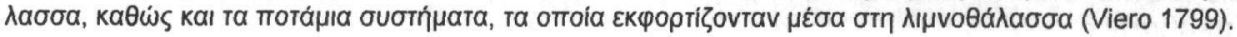

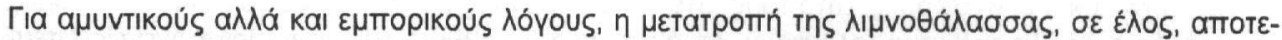

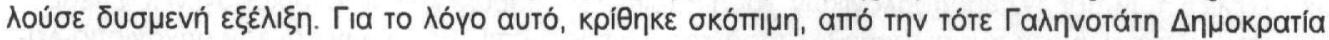

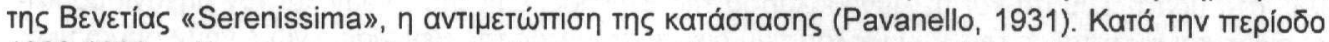

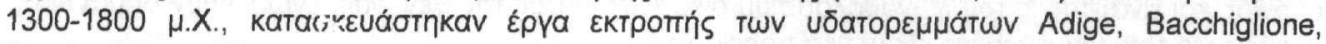

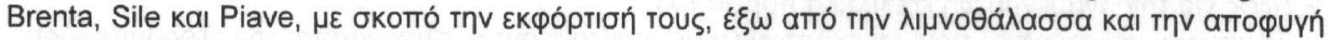

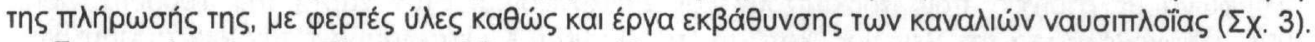

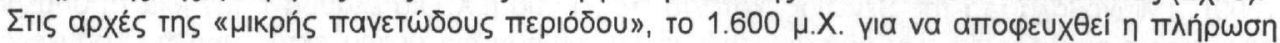

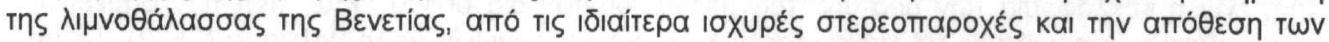

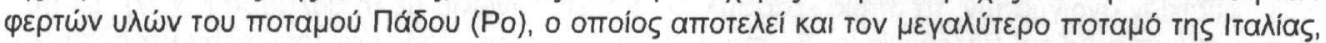

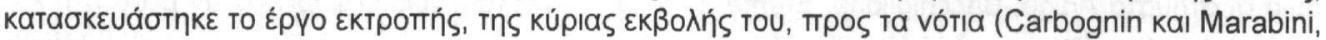
1989).

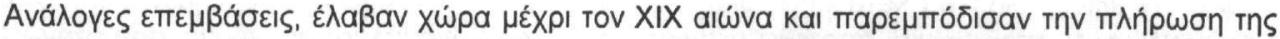

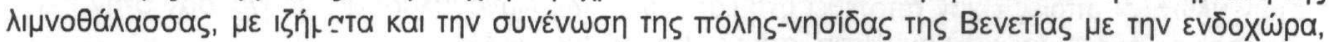

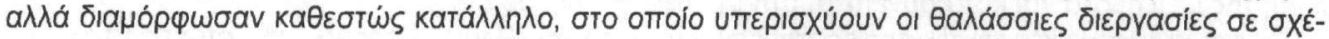

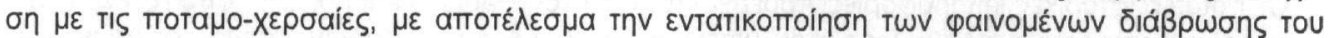

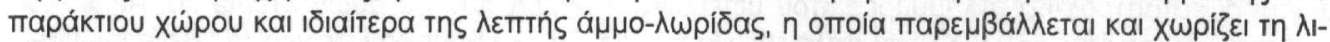

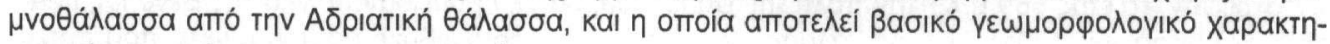

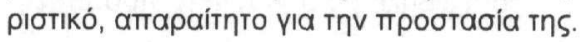




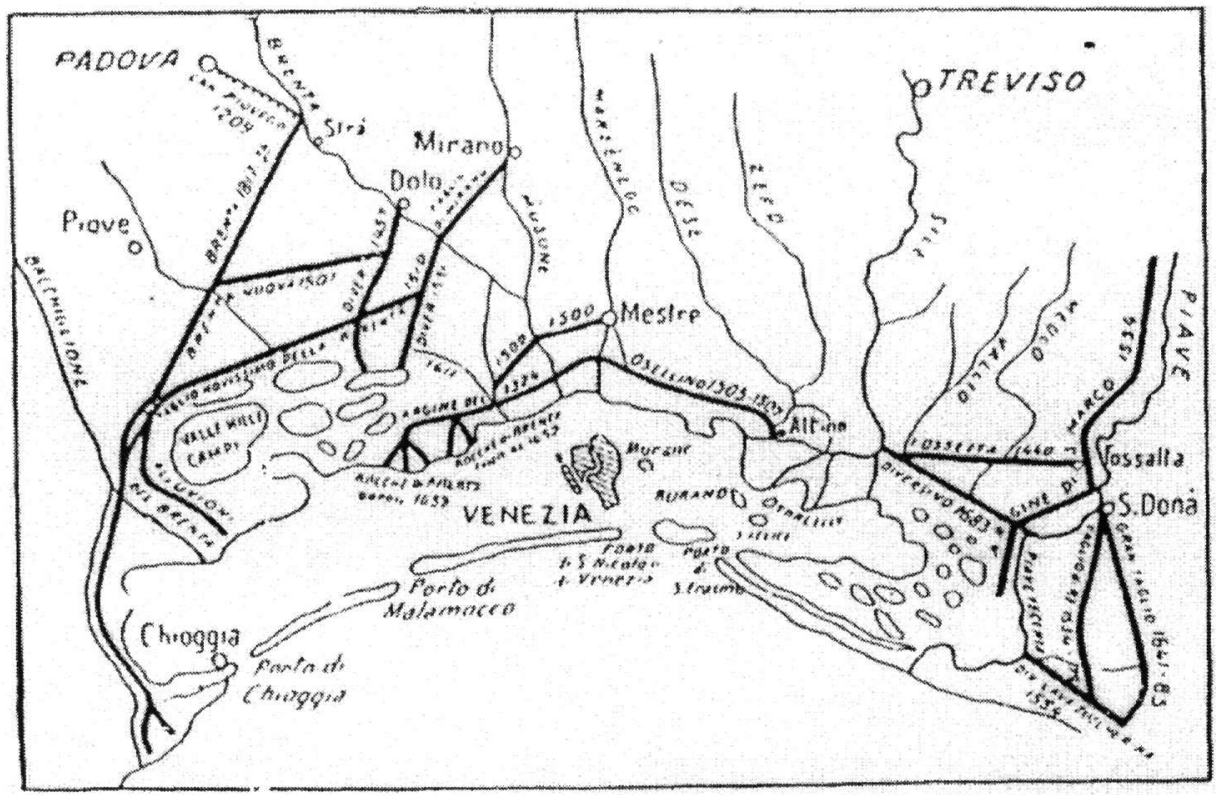

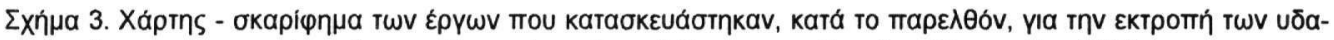

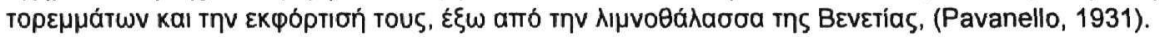

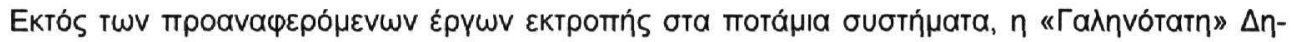

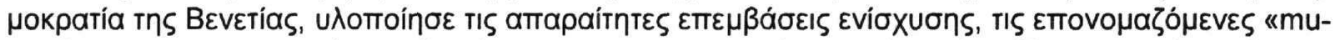

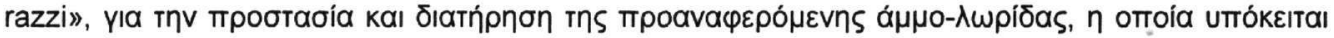

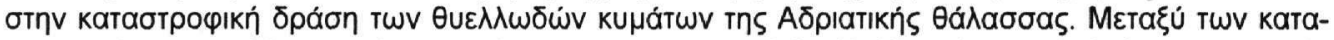

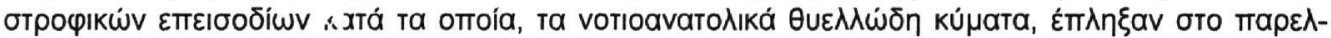

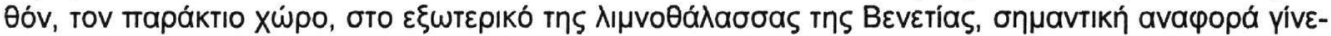

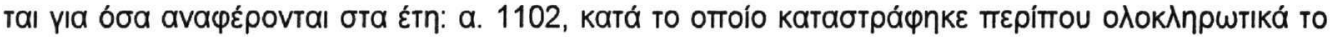

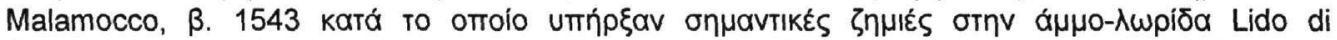

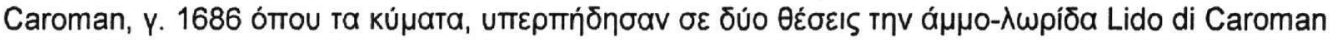

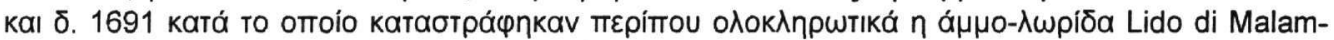

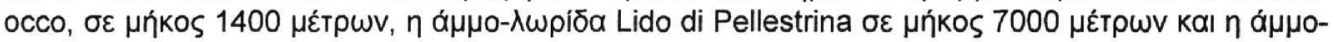

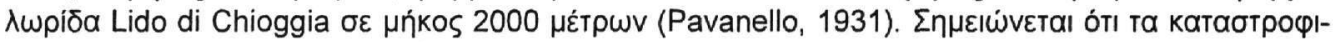

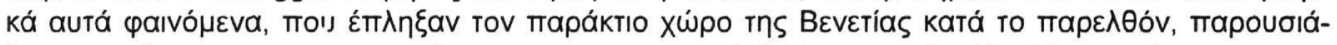

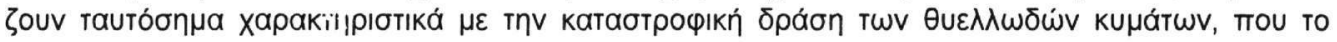

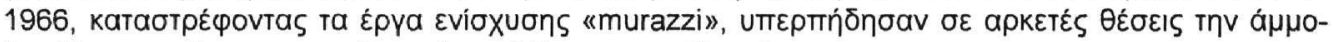

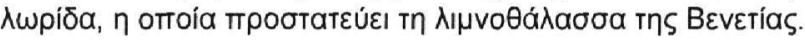

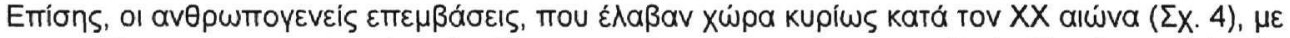

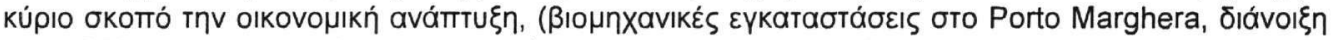

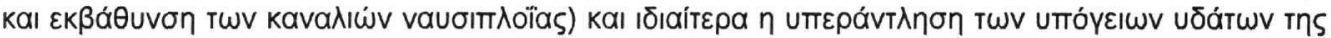

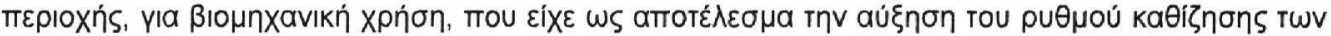

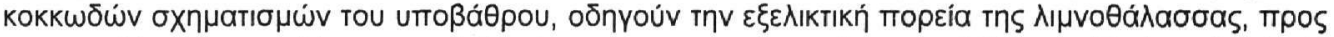

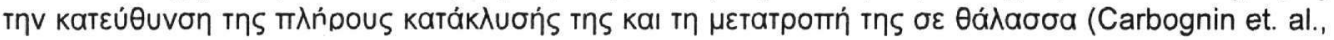
1985). 


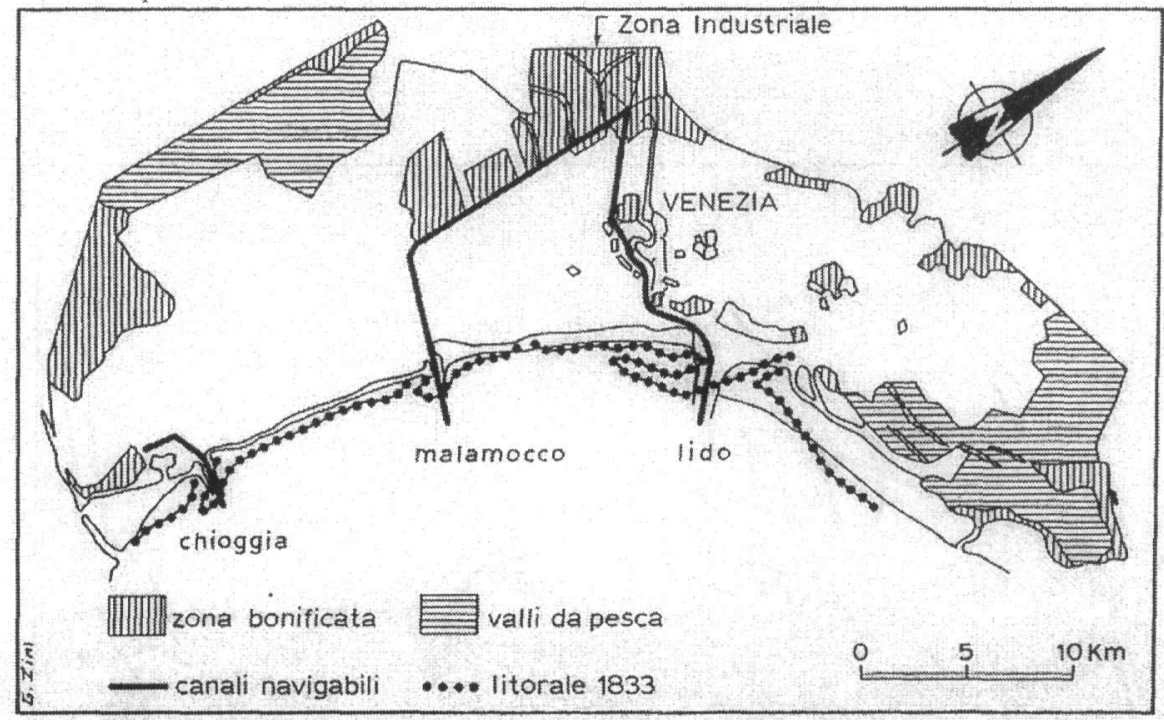

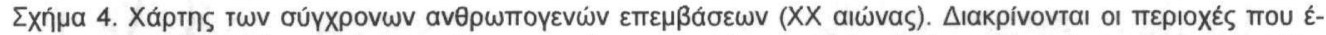

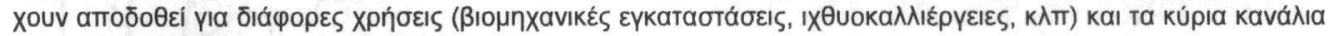
vauoırıoîas (Carbognin et. al., 1985).

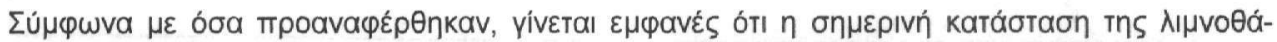

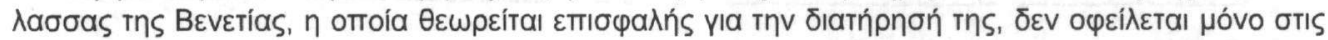

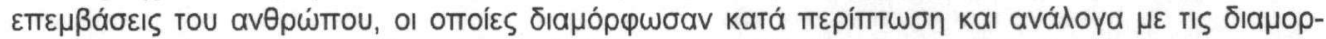

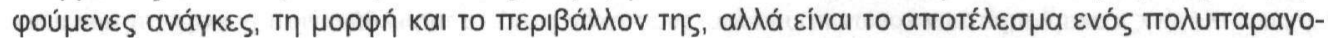

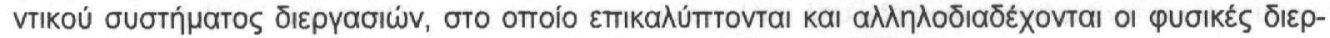

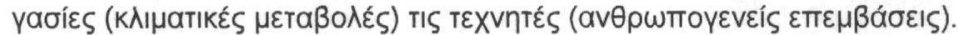

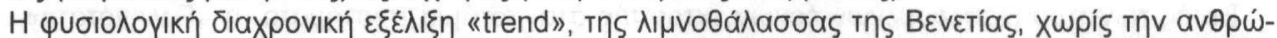

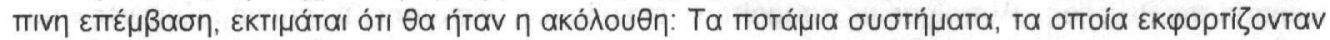

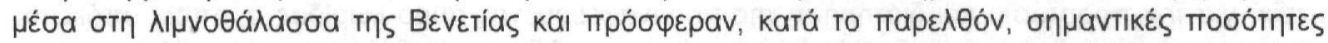

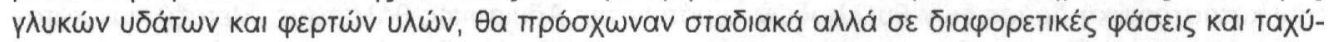

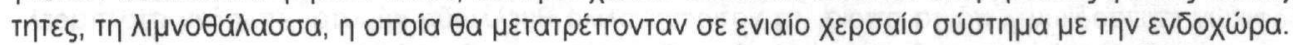

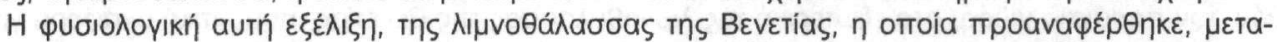

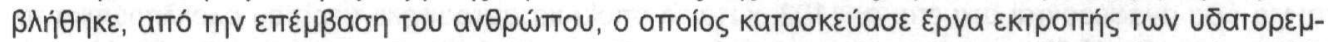

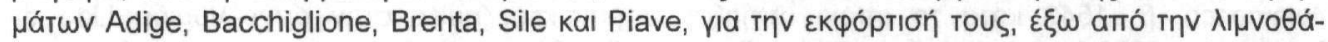

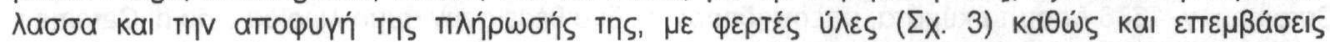

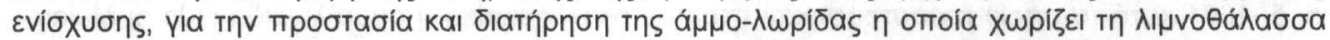

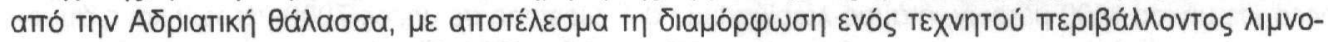

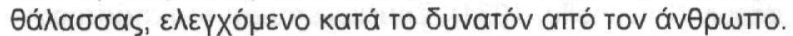

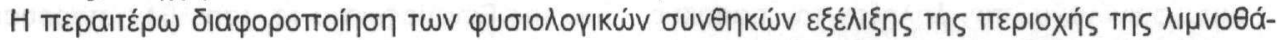

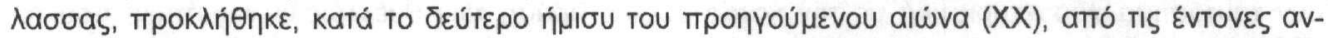

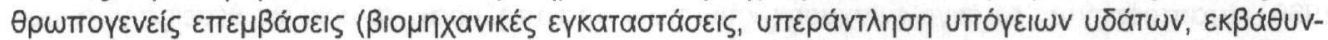

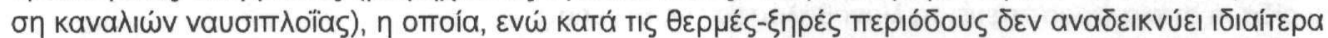

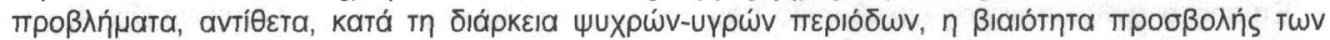

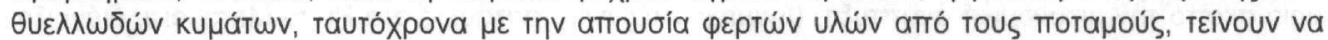

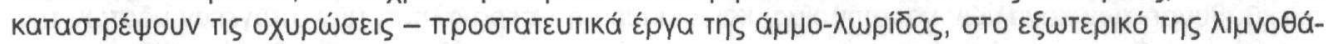

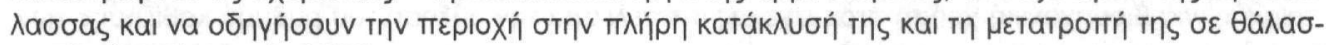
бa (Carbognin et. al., 1985).

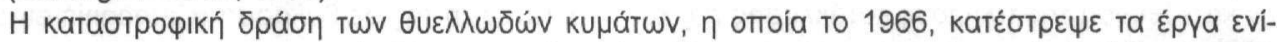

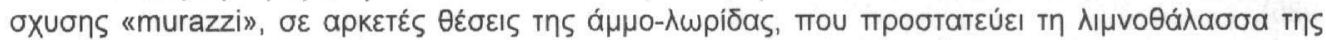

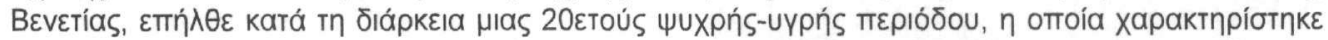

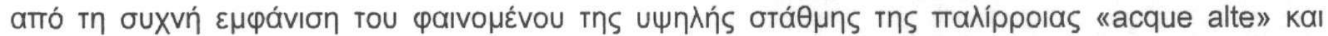

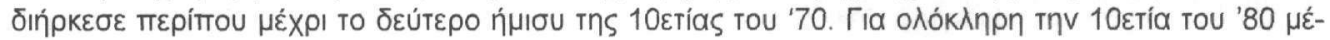




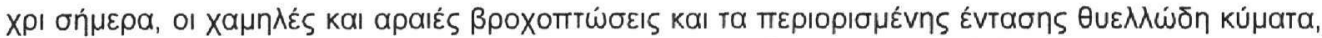

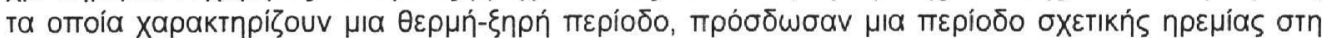

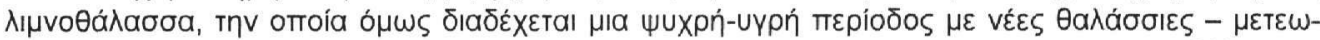

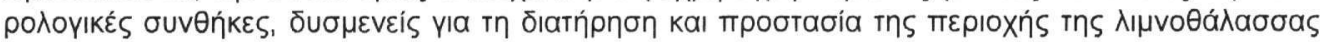
TnS Bevetías (Lamb 1977, Lamb 1982, Camuffo 1987).

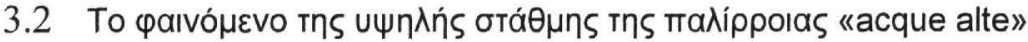

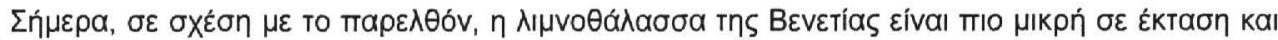

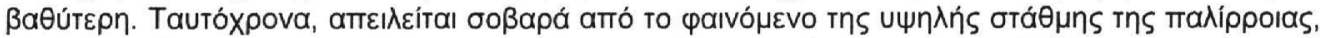

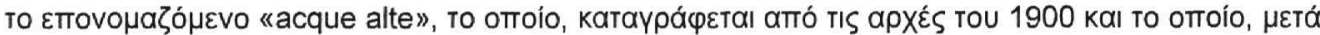

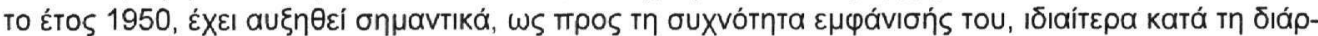

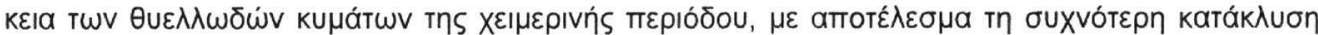

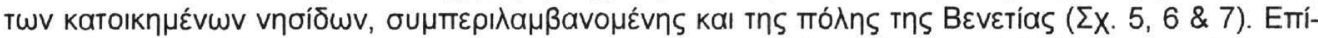

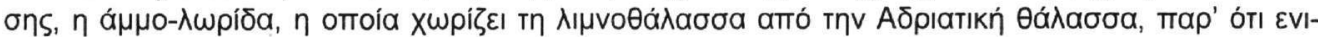

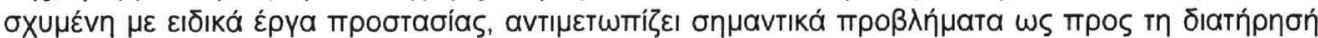

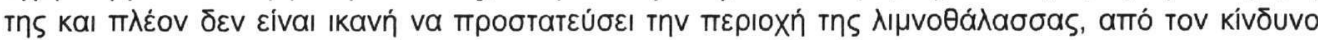

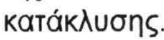

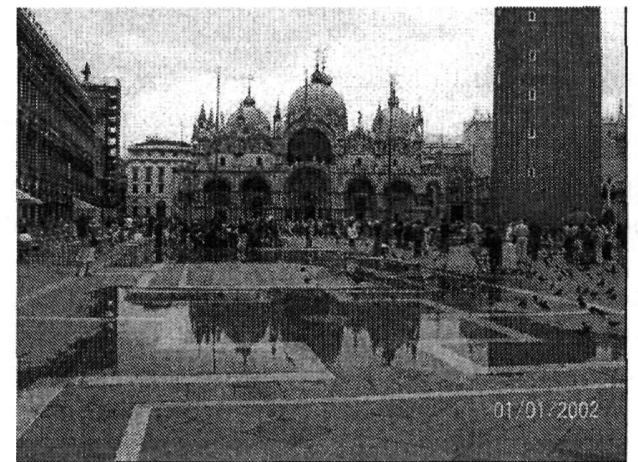

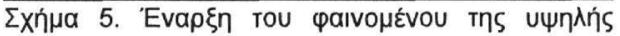

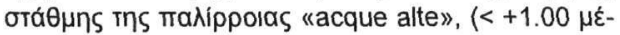

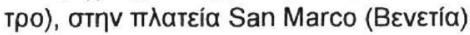

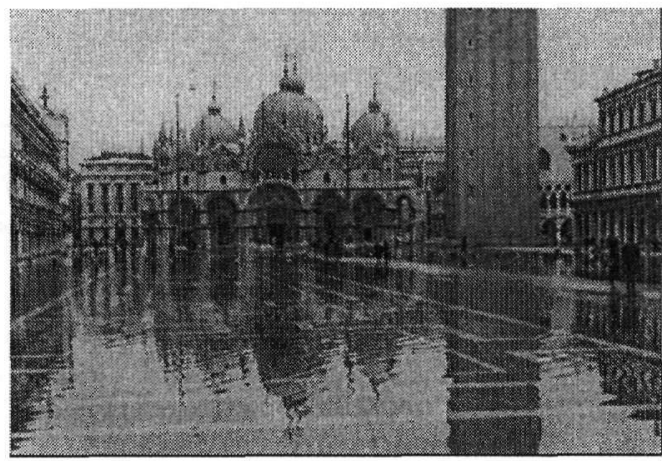

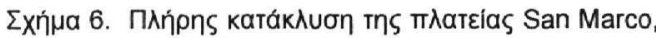

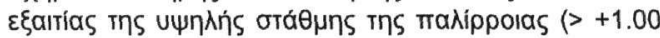
$\mu \dot{\tau}$ тро)

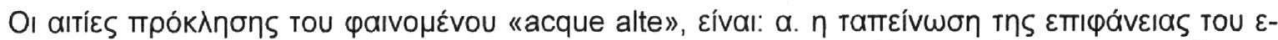

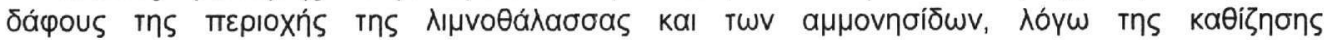

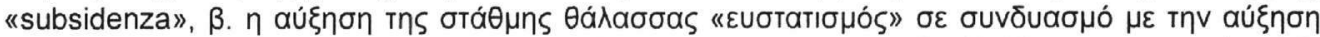

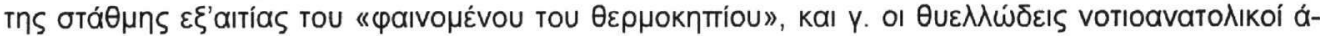

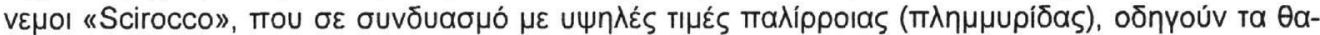

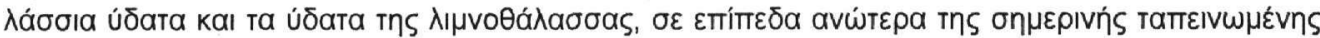

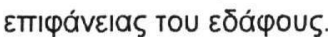

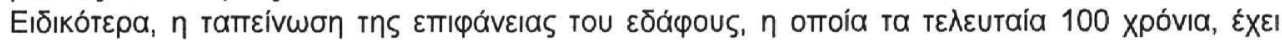

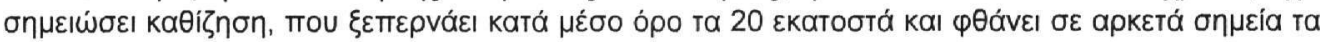

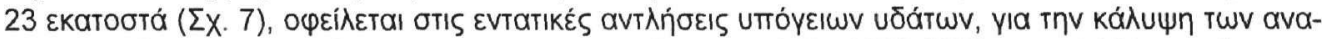

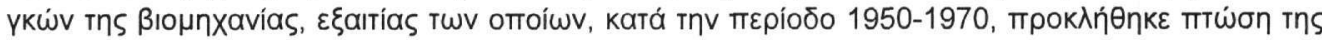

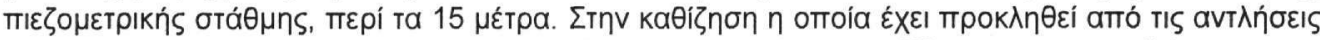

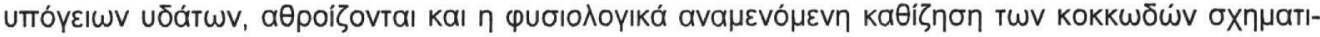

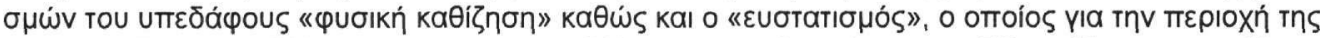

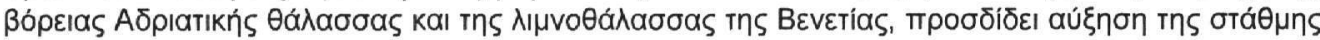

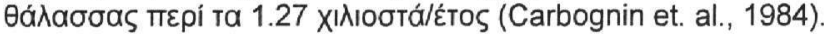




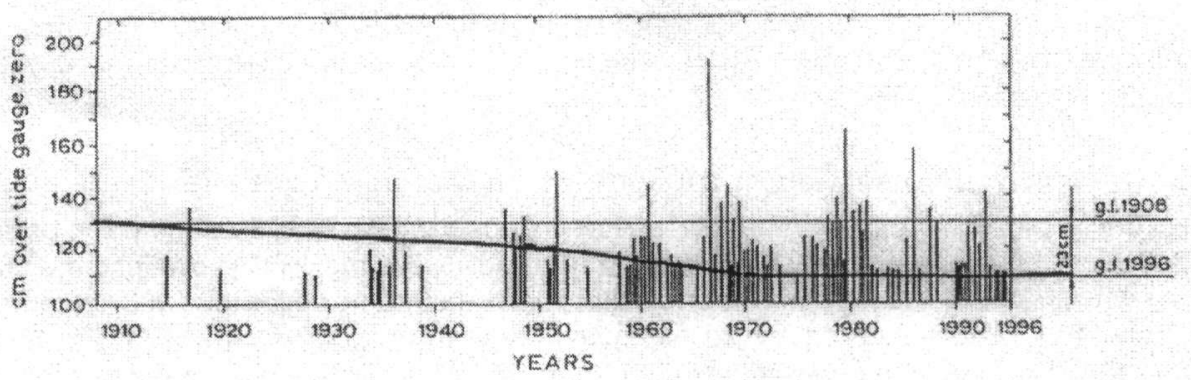

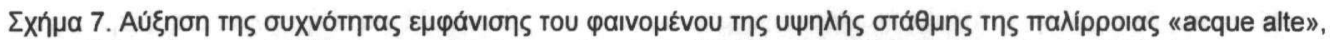

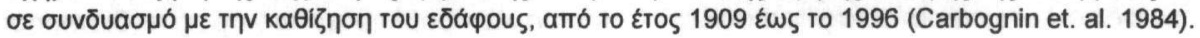

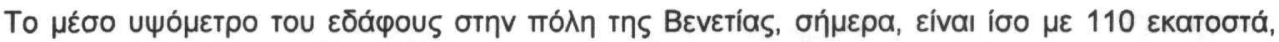

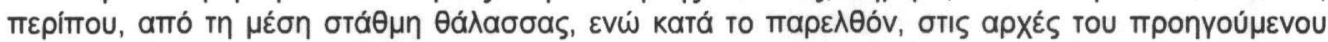

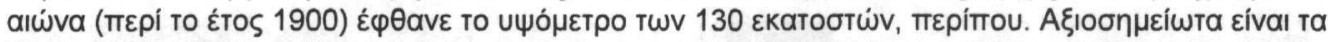

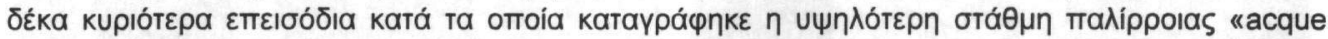

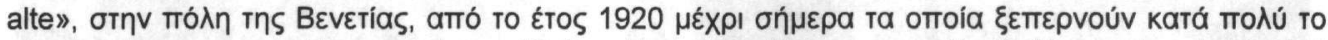

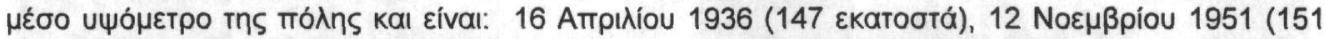

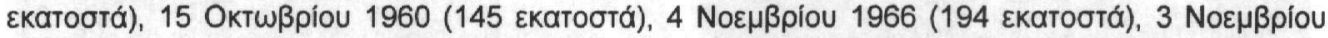

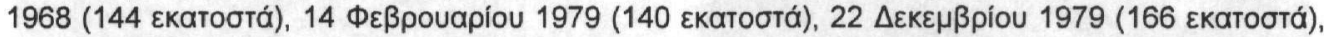

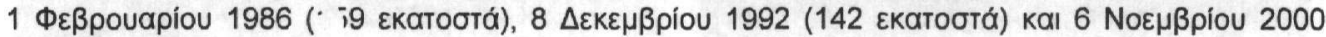
(144 عкатобта́).

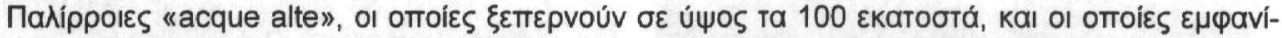

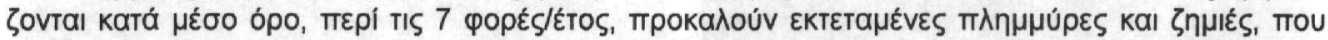

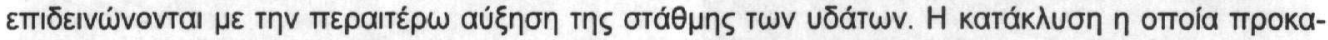

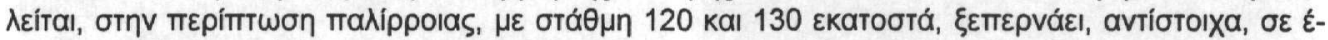

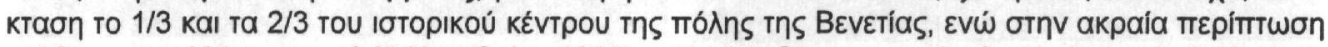

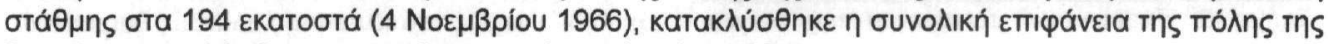

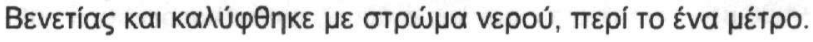

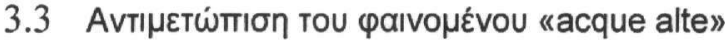

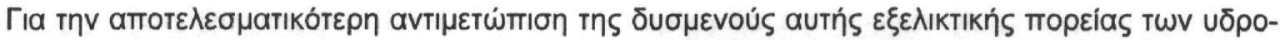

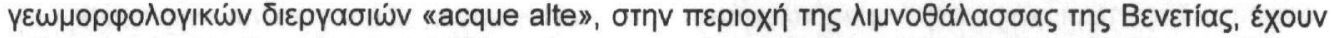

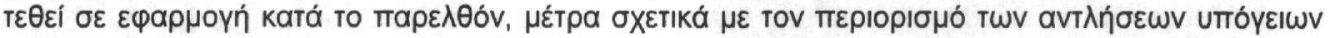

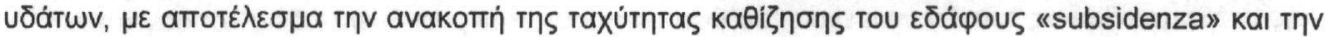

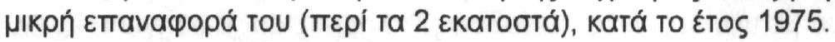

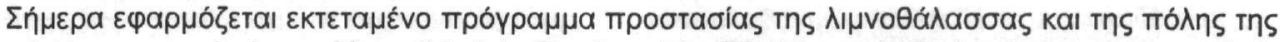

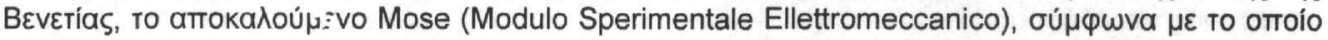

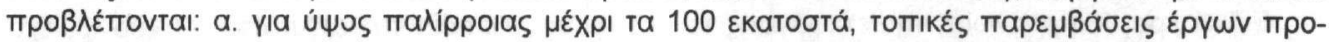

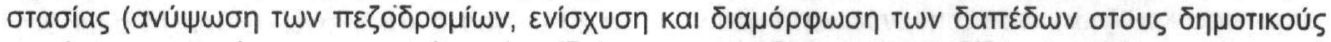

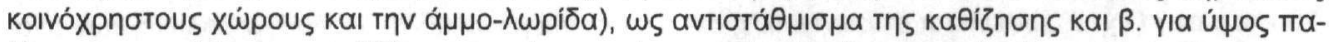

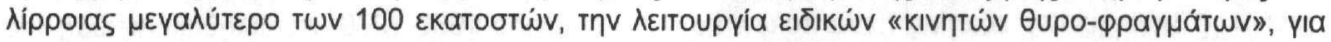

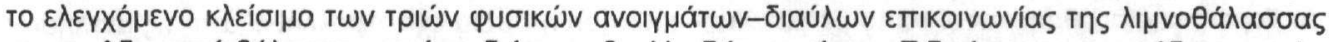

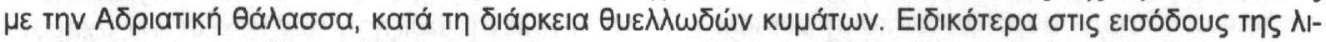

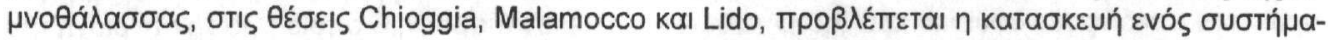

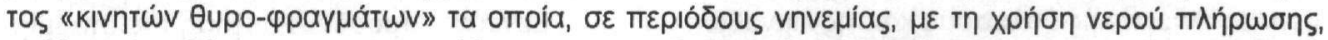

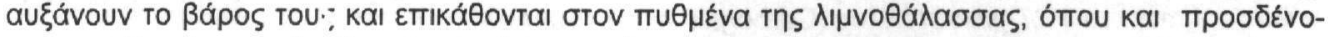

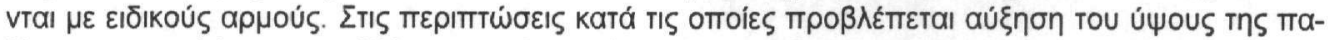

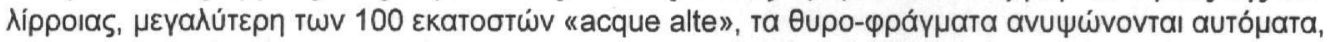

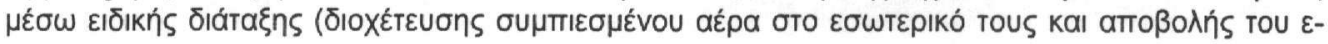




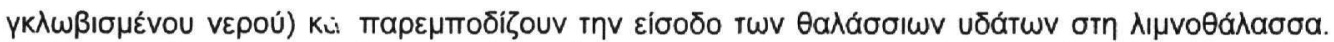

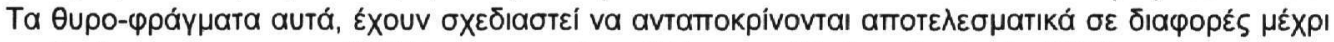

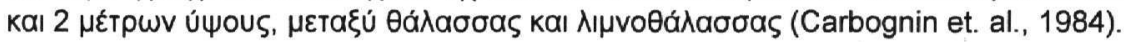

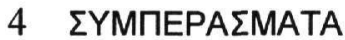

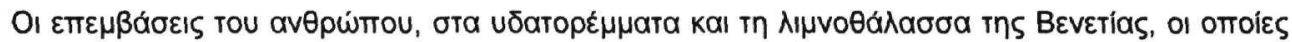

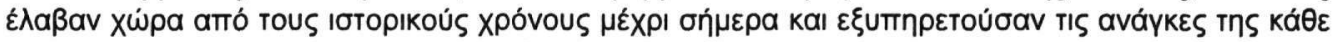

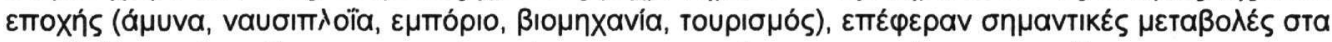

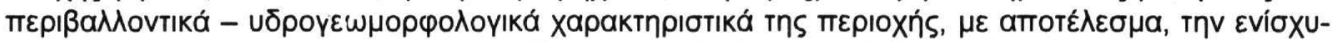

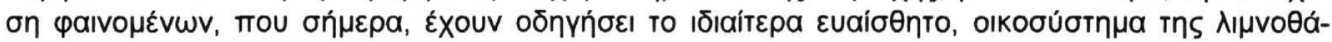

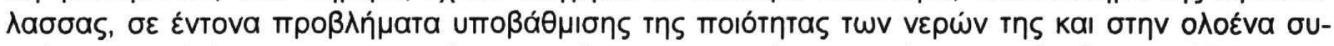

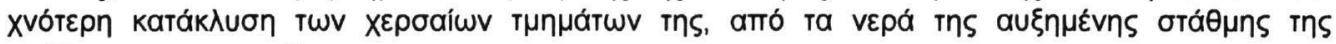
maגippoias «acque alte».

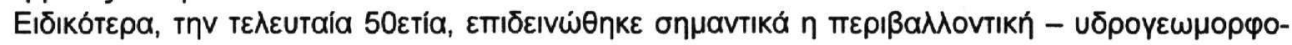

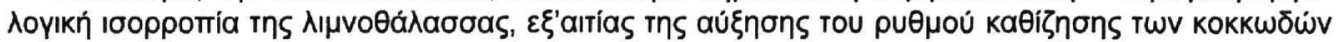

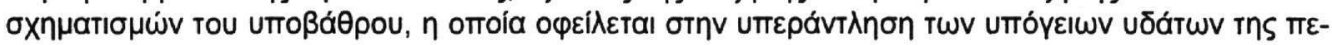

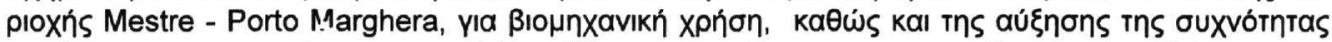

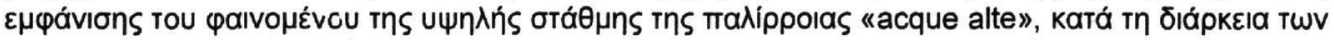

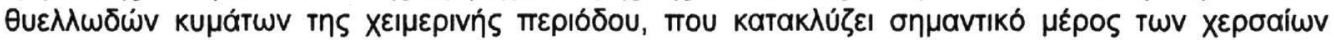

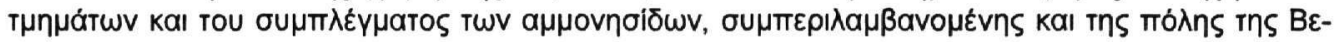
vetías.

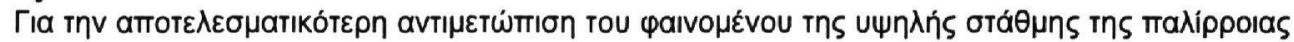

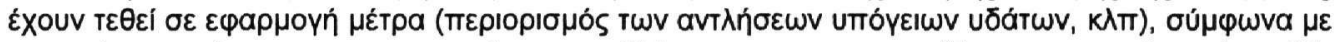

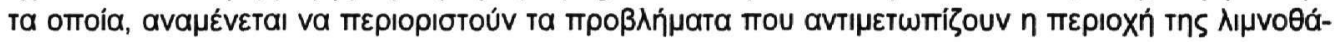

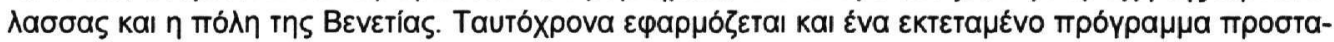

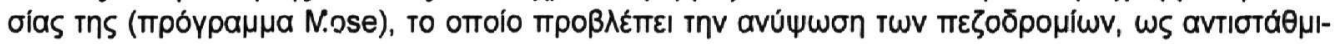

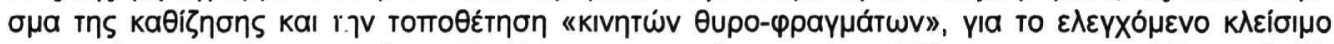

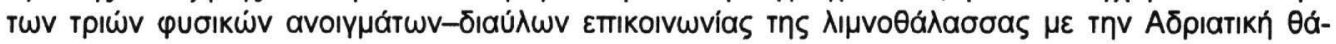

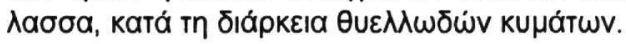

\section{ANAФOPE $\Sigma$}

Camuffo D., 1987. Freezing of the Venetian Lagoon since the $9^{\text {th }}$ century A.D. in comparison to the climate of Western Europe and England, Climatic Change, 10, 43-46.

Carbognin L., Gatto P., Merabini F., 1984. The city and the lagoon of Venice - a guidebook on the environment and land subsidence, hi Congresso Internazionale sulla subsidenza, Venezia, pp. 1-35.

Carbognin L., Gatto P., Marabini F., 1985. Erosive processes in the littoral of the Venice lagoon, Coastal zone 85, IV Symposium on coastal and ocean management, Baltimore, U.S.A., pp. 1587-1600.

Carbognin L., Marabini F., 1989. Evolutional trend of the Po river delta (Adriatic sea, Italy), Proc. of the $28^{\text {th }}$ International Geological Congress, Washington D.C., U.S.A., pp. 238-239.

Enzi S., Marabini F., 1992. Evoluzione della fascia costiera Adriatica e l'azione antropica, Proc. of the Congress Asociazione Italiana di Cartografia, Bolzano, Italy.

Lamb H. H., 1977. Climate. Present, Past and Future, London, Methuen, vol. 2.

Lamb H. H., 1982. Climate, history and the modern world, London, Methuen.

Marabini F., Veggiani A., i,991. Evolutional trend of the coastal zone and influence of the climatic fluctuations, Proc. of the C.O.S.U., II-Iong Beach, U.S.A., 2-4 April.

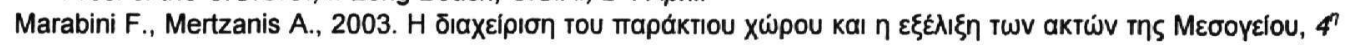

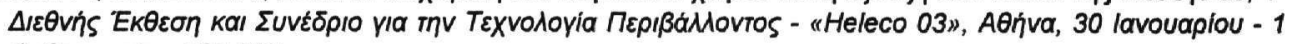
Фвßpouapiou, 529-535.

Pavanello G., 1931. La laguna veneta. Note illustrative e breve sommario storico, Magistrato alle acque, Ufficio speciale idrografico, pp. 1-34. 


\title{
THE LAGOON OF :/ENICE : EVOLUTION IN TIME OF THE HYDROGEOMORPHOLOGICAL PROCESSES, IN THE WATERSTREAMS AND THE LAGOON OF VENICE (ITALY)
}

\author{
Marabini F. ${ }^{1}$ and Mertzanis A. ${ }^{2}$ \\ ${ }^{1}$ Consiglio Nazionale delle Ricerche, Istituto di Geologia Marina, Via P. Gobetti 101, 40129 \\ Bologna, Italy, franco.marabini@bo.ismar.cnr.it \\ 2 Technological Educational Institute of Lamia, Annex of Karpenisi, Department of Forestry, \\ 36100, Karpenisi, Greec? amertz@hol.gr
}

This work depicts the evolution in time of the hydrogeomorphological processes and the human impact which from the historical era have contributed to the actual configuration of the Lagoon of Venice (northwestern Adriatic sea). Those natural hydrogeomorphological processes, in combination with the intense human interference, have led to the increase in the rate of occurrence of the phenomenon of the high level of tide, a phenomenon known as "acque alte", which is prominent today in the Lagoon area and the complex of the "sand islands" which are formed inside the Lagoon. This work also describes the measures prescribed and taken, according to environmental protection program (Mose), in order to deal more effectively with this undesirable hydrogeomorphological processes in the area o; the Lagoon of Venice. 